\title{
Antimicrobial evaluation of leaves of Balanites aegyptiaca (Linn.) Delile. \& Moringa oleifera Lam.
}

\author{
Research Article
}

\author{
Malvika Saini $^{1 *}$, Tarun Sharma ${ }^{1}$, Gaurav Sharma $^{2}$, Mita Kotecha $^{3}$
}

1. PG Scholar, 2. Pharmacologist, 3. Professor and HOD

Department of Dravyaguna Vigyan, National Institute of Ayurveda, Jaipur

\begin{abstract}
Background : Balanites aegyptiaca (Linn.) Delile. \& Moringa oleifera Lam. are well known drugs in Ayurveda for their wound healing property as they possess krimighna action or ability to kill foreign pathogens. Ingudi \& Shigru leaves are used for wound healing purpose. Therefore leaves of both the plants were selected for antimicrobial study against surgical wound infection causative organisms. Methods: Both aqueous and alcoholic extracts of leaves of both plants at 10,20,30\% concentrations were tested for antimicrobial activity by agar well diffusion method against a range of gram-positive and gram-negative bacteria. Zone of inhibition of extracts were determined, then activity index \& $\mathrm{IC}_{50}$ value was calculated. Results: Both ethanol and aqueous extracts of Balanites aegyptiaca (Linn.) Delile. \& Moringa oleifera Lam. inhibited the growth of all the tested strains of bacteria. Aqueous extract of Balanites aegyptiaca (Linn.) Delile has more potent action against microorganism Staphylococcus aureus, Escherichia coli, Klebsiella aerogenes, ZOI $(15 \mathrm{~mm}, 11 \mathrm{~mm}, 19 \mathrm{~mm}$ respectively), AI $(0.6$, 0.61, 0.70 resp.), IC50 (1.778, 1.586, 1.196 resp.). Conclusion: Leaves of Balanites aegyptiaca (Linn.) Delile possess good antimicrobial effects against microorganism Staphylococcus aureus, Escherichia coli, Klebsiella aerogenes compared to Moringa oleifera Lam. Efficacy is very much significant against Klebsiella aerogenes.
\end{abstract}

Keywords: Balanites aegyptiaca (Linn.) Delile. \& Moringa oleifera Lam., bacteria, antimicrobial activity, Zone of inhibition, activity index, $\mathrm{IC}_{50}$ value.

\section{Introduction :}

Balanites aegyptiaca (Linn.) Delile. is a small spiny tree belonging to family balanitaceae, found in forest outskirts in drier parts of peninsular India, Rajasthan, from south east Punjab to West Bengal, Sikkim.

In Ayurveda, plant is popularly known as Ingudi (Sanskrit), Hingoran (Hindi); Desert date (English); Nanjunta (Malyalam). The Plant contain Saponins- balanitisins, diosegenin, cryptogenin in fruit \& fruit pulp. Deltonin, protodeltonin, balanitol, trans feruloyltyramine, vanillic acid, syringic acid in stem bark. Saponin of diosegenin, stigmasterol, free diosgenin in leaves. Nitrogenin glucoside, balanitins-1, 2,3 , yamogenin in plants.

It possess antibacterial, antifungal, hyperglycemic, spasmolytic, piscicidal, antimicrobial, cytotoxic, antitumour, hypotensive, haemolytic, antileishmanial, molluscicidal, antifeedant, emetic, larvicidal, cercaricidal, hepatoprotective action (1).

Moringa oleifera Lam. is slender \& fast growing shrub belonging to family Moringaceae. Plant

*Corresponding Author:

Malvika Saini,

P.G. Scholar,

Department of Dravyaguna Vigyan,

National Institute of Ayurveda,

Jaipur, Rajasthan, India

E-mail: malvikasaini.ms@gmail.com is indigenous in sub-himalayan tract. It is commonly cultivated throughout the country. Plant is found in Assam, Gujrat and Uttar pradesh. It grows almost, throughout India. It is the only drug who's each \& every part's monograph is available in Ayurvedic Pharmocoepia of India.

In Ayurveda plant is popularly known as Shigru (Sanskrit); drum stick tree(English); Sahijan (Hindi), Sajinna(Bengali), Muranga (Kannad), Murankai (Tamil).

The plant contains 4- hydroxymellein, vanillin, moringine, moringinine, bayrenol, indole acetic acid, indole acetonitrile, benzylisothiocynate, pterygospermine, cartotene, flavonoids, polysaccharide, protein components, fatty acids, spirochein, pterygospermine exhibits antibiotic activity.

It has hypotensive, antibacterial, antifungal, antiviral, depressant, hepatoprotective, antiinflammatory, anticancer, antibiotic, stimulant, antitubercular, antifertility action (2).

Leaves are anti-inflammatory, anodyne, anthelmintic, ophthalmic, rich in vitamin A\&C. They are useful in scurvy, wounds, tumours, inflammations, helminthiasis.

Seed oil of kernel of Ingudi is used in treatment of skin diseases, burn, excoriation, chronic vitiated ulcers \& freckles \& is indicated from Nighantu period. But significant work has not been done so far on Ingudi leaves. Shigru leaf is also a potent antimicrobial agent or Krimighna action known from ancient times. Therefore both plants were taken for study to prove 
their wound healing \& antimicrobial activity with specific bacterial strains which are causative organism for surgical wound infections

\section{Picture 1.1 showing leaves \& spines of Ingudi}

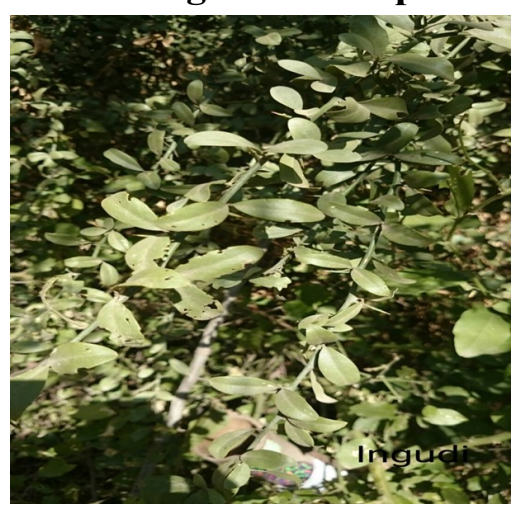

Picture 1.2 showing leaves of Shigru

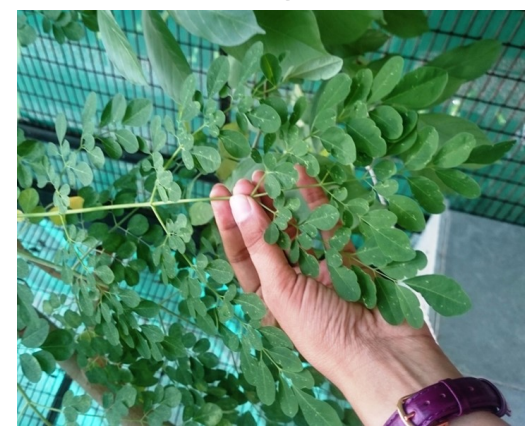

\section{Material \& methods \\ Plant material}

Leaves of Shigru \& Ingudi were collected from Jhag village, Dudu tehsil, Jaipur \& were authenticated at herbarium section, Department of Botany, Rajasthan University, Jaipur with authentication no. RUBL211520 \& RUBL 211519 respectively.

\section{Preparation of extracts}

Cold maceration method was used for preparing extracts. Macerated $10 \mathrm{~g}$ of the air dried drug, coarsely powdered, with $200 \mathrm{ml}$ of solvent i.e. for preparing ethanol extract, ethanol solvent was used \& for preparing aqueous extract, distilled water was used. Procedure was done for the specified strength in a closed flask for twenty-four hours, shaking frequently during six hours and allowed to stand for eighteen hours. Filtered rapidly, taking precautions against loss of solvent, evaporated the filtrate to dryness in a tarred flat bottomed shallow dish, and dried at $105^{\circ} \mathrm{C}$, to constant weight \& weighed (3). The yield was $15.1 \%$ for ethanol extract of Moringa oleifera Lam., 23.26\% for aqueous extract of Moringa oleifera Lam., 21.58\% for ethanol extract of Balanites aegyptiaca (Linn.) Delile, $19.94 \%$ for aqueous extractof Balanites aegyptiaca (Linn.) Delile. Repeated the procedure for 5 times so as to collect the enough amount of extract required for antimicrobial activity. For carrying out antimicrobial activity, $10 \%, 20 \%, 30 \%$ concentrations of both ethanol \& aqueous extracts were prepared by dissolving them in ethanol/water.

\section{Antimicrobial activity}

Micro-organisms-bacterial strains selected for the study were Pseudomonas aeruginosa, Escherichia coli, Staphylococcus aureus, Klebsiella aerogenes. Out of which Pseudomonas aeruginosa, Escherichia coli, Klebsiella aerogenes are gram negative bacteria, whereas Staphylococcus aureus is gram positive bacteria. Reason for selecting these strains was, they are causative organism for surgical wound infections \& mostly causes infections in piles, fistula-in-ano etc.

The pathogenic strains of above bacteria were procured from 'Institute of Microbial Technology' (IMTECH), Chandigarh and the stock cultures maintenance $\&$ antibacterial study was done at 'microbiology lab, Dravyaguna Vigyan Deptt, NIA, Jaipur.

- MTCC No. 39-Klebsiella aerogenes

- MTCC No. 10239-Escherichia coli

- MTCC No. 1034- Pseudomonas aeruginosa

- MTCC No. 6908-Staphylococcus aureus

\section{Revival of microbial cultures}

Microbes collected from Institute of Microbial Technology were in dried form. It needed to be revived. Like all other living forms, micro-organisms need suitable nutrients and favourable environments for growth. A simple way to obtain bacteria is to grow them in a flask in broth medium.

$100 \mathrm{ml}$ Nutrient broth medium were transferred in conical flasks (of quantity $100 \mathrm{ml}$ ) $20 \mathrm{ml}$ each. The flasks were capped with cotton plug and autoclaved at $121^{\circ} \mathrm{C}$ for 20 minutes at $15 \mathrm{lb}$ pressure per square inch. Dried \& frozen bacteria were transferred to conical flasks with nutrient broth media, kept at $37^{\circ} \mathrm{C}$ to get cultures.

\section{Preparation of media $\&$ media plates}

Muller-Hington agar medium was taken for all pathogens. 38 gram of agar was dissolved in 1 litre of distilled water. Heated the agar with water at $100^{\circ} \mathrm{C}$ till it becomes transparent, then kept it in hot air oven for 15 minutes. The sterilized media were poured in sterile petri dishes aseptically. The Agar (solidifying agent), which was added in a broth medium, hardens at it cools. After solidifying of agar plates (nearly about 15 to 20 minutes), they were kept inverted in incubator at $37^{\circ} \mathrm{C}$ for overnight for checking any contamination. The agar plates were ready.

Applied a microbial culture to the surface in a petri plate and spread them with cotton swab sticks. The prepared plates were then incubated in inverted position at $37^{\circ} \mathrm{C}$ for 24 hours. After incubation, we got the pure cultures. This procedure is termed as 'Sub culturing'. In 
this way, frequent sub-culturing was done whenever required during antibacterial study.

\section{Well diffusion method}

For bactericidal assay in vitro, well diffusion method was adopted (4), because of reproducibility and precision. Wells (of about $4 \mathrm{~mm}$ diameter) were made on the plates with the help of sterile stainless steel borer. The different test organisms were proceeded separately using a sterile swab over previously sterilized culture medium plates. About 20-30 $\mu 1$ different concentrations of plant solvent extracts were added using sterile syringe into the wells and allowed to diffuse at room temperature for $2 \mathrm{hrs}$ (5).Control experiments comprising inoculums without plant extract were set up. The plates were incubated at $37^{\circ} \mathrm{C}$ for 48 hours for bacterial pathogens. The zone of inhibition were measured around sterilized wells $(4 \mathrm{~mm}$ in diameter). The 4 readings were taken in different planes, and then the mean was calculated.

\section{Group design}

Test group- $10 \%, 20 \%, 30 \%$ concentrations of ethanol extracts of leaves of Balanites aegyptiaca (Linn.) Delile.

$10 \%, 20 \%, 30 \%$ concentrations of aqueous extracts of leaves of Balanites aegyptiaca (Linn.) Delile.

$10 \%, 20 \%, 30 \%$ concentrations of ethanol extracts of leaves of Moringa oleifera Lam.

$10 \%, 20 \%, 30 \%$ concentrations of aqueous extracts of leaves of Moringa oleifera Lam.

Standard group- 5\% w/v Vancomycin

Negative control group- Distilled water \& Ethanol
Determination of activity index

The activity index of the crude plant extract was calculated as (6):

Activity index (A.I.) = Mean of zone of inhibition of the extract/ Zone of inhibition obtained for standard antibiotic drug.

$\mathrm{IC}_{\mathbf{5 0}}$ :

The half maximal inhibitory concentration $\left(\mathbf{I C}_{\mathbf{5 0}}\right)$ is a measure of the effectiveness of a substance in inhibiting a specific biological or biochemical function. This quantitative measure indicates how much of a particular drug or other substance (inhibitor) is needed to inhibit a given biological process (or component of a process, i.e. an enzyme, cell, cell receptor or microorganism) by half.

The $\mathrm{IC}_{50}$ of a drug can be determined by constructing a dose-response curve and examining the effect of different concentrations of antagonist on reversing agonist activity. $\mathrm{IC}_{50}$ values can be calculated for a given antagonist by determining the concentration needed to inhibit half of the maximum biological response of the agonist. $\mathrm{IC}_{50}$ values can be used to compare the potency of two antagonists (7). In general, the higher the concentration of inhibitor, the more agonist activity will be lowered. $\mathrm{IC}_{50}$ value increases as agonist concentration increases.

\section{Determination of $\mathbf{I C}_{\mathbf{5 0}}$}

$\mathrm{y}$-axis $=\%$ inhibition and $\mathrm{x}$-axis $=\log$ conc. linear equation $\mathrm{y}=\mathrm{mx}+\mathrm{c}$. $\mathrm{Y}=50, \mathrm{x}=\log$ conc. $\mathrm{IC}_{50^{-}}$Antilog of $\mathrm{X}$

\section{Results}

\section{Zone of Inhibition (in mm):}

Table 1.1 showing zone of inhibition of test drugs \& positive, negative control groups Where AESL- aqueous extract of Shigru leaves, EESL- ethanol extract of Shigru leaves, AEIL- aqueous extract of Ingudi leaves, EEILethanol extract of Ingudi leaves at 10\%, 20\%, 30\% concentrations.

\begin{tabular}{|c|c|c|c|c|c|c|c|c|c|c|c|c|c|c|}
\hline $\begin{array}{c}\text { Bacterial } \\
\text { strains }\end{array}$ & \multicolumn{3}{|c|}{ AESL } & \multicolumn{3}{c|}{ EESL } & \multicolumn{3}{c|}{ AEIL } & \multicolumn{3}{c|}{ EEIL } & $\begin{array}{c}\text {-ve } \\
\text { Control }\end{array}$ & $\begin{array}{c}\text { +ve } \\
\text { Control }\end{array}$ \\
\hline & 10 & 20 & 30 & 10 & 20 & 30 & 10 & 20 & 30 & 10 & 20 & 30 & $0 \%$ & $5 \% \mathrm{w} / \mathrm{v}$ \\
$\%$ & $\%$ & $\%$ & $\%$ & $\%$ & $\%$ & $\%$ & $\%$ & $\%$ & $\%$ & $\%$ & $\%$ & \\
\hline $\begin{array}{c}\text { Pseudomonas } \\
\text { aeruginosa }\end{array}$ & 7 & 9 & 11 & 7 & 8 & 8 & 6 & 8 & 9 & 0 & 8 & 12 & 0 & 20 \\
\hline $\begin{array}{c}\text { Staphylococcus } \\
\text { aureus }\end{array}$ & 7 & 8 & 11 & 6 & 7 & 7 & 9 & 9 & 15 & 10 & 11 & 11 & 0 & 25 \\
\hline $\begin{array}{c}\text { Escherichia } \\
\text { Coli }\end{array}$ & 0 & 7 & 9 & 7 & 7 & 9 & 7 & 9 & 11 & 6 & 8 & 8 & 0 & 18 \\
\hline $\begin{array}{c}\text { Klebsiella } \\
\text { aerogenes }\end{array}$ & 6 & 7 & 9 & 6 & 8 & 10 & 16 & 18 & 19 & 9 & 10 & 15 & 0 & 27 \\
\hline
\end{tabular}


Graph 1.1 showing zone of inhibition of test samples with positive \& negative controls where $\mathrm{C}$ stands for control group

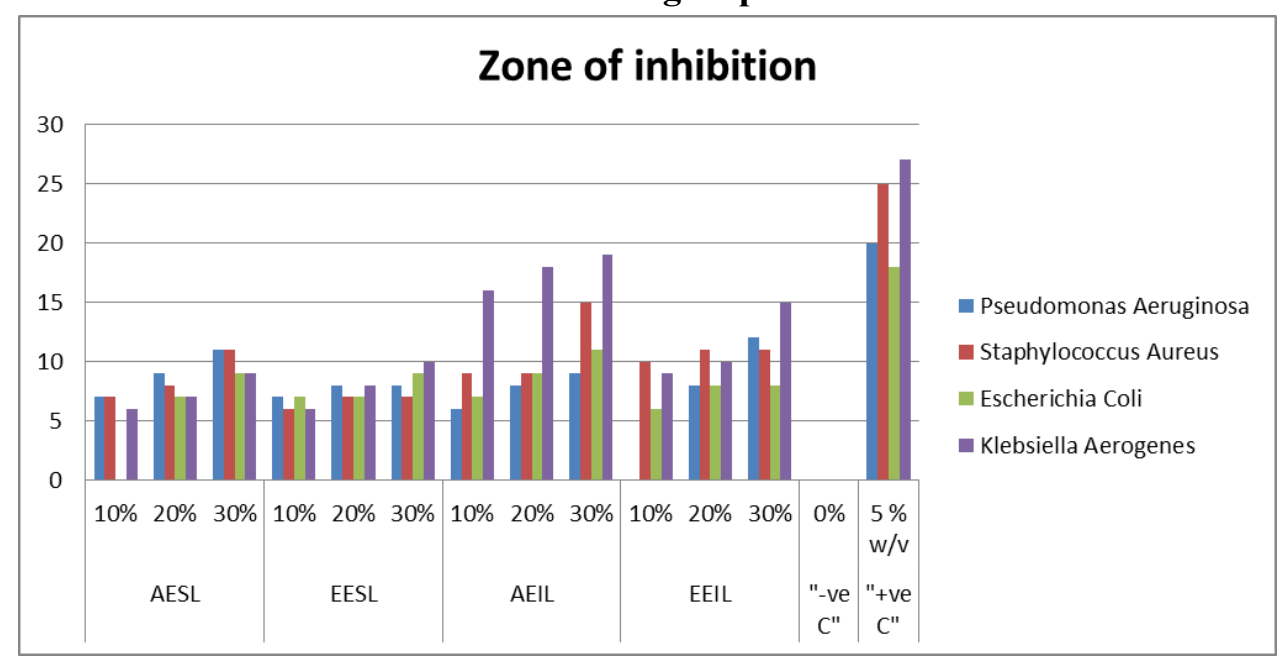

Picture1.3 Showing of zone of inhibition of + ve \& -ve control against four strains of bacteria
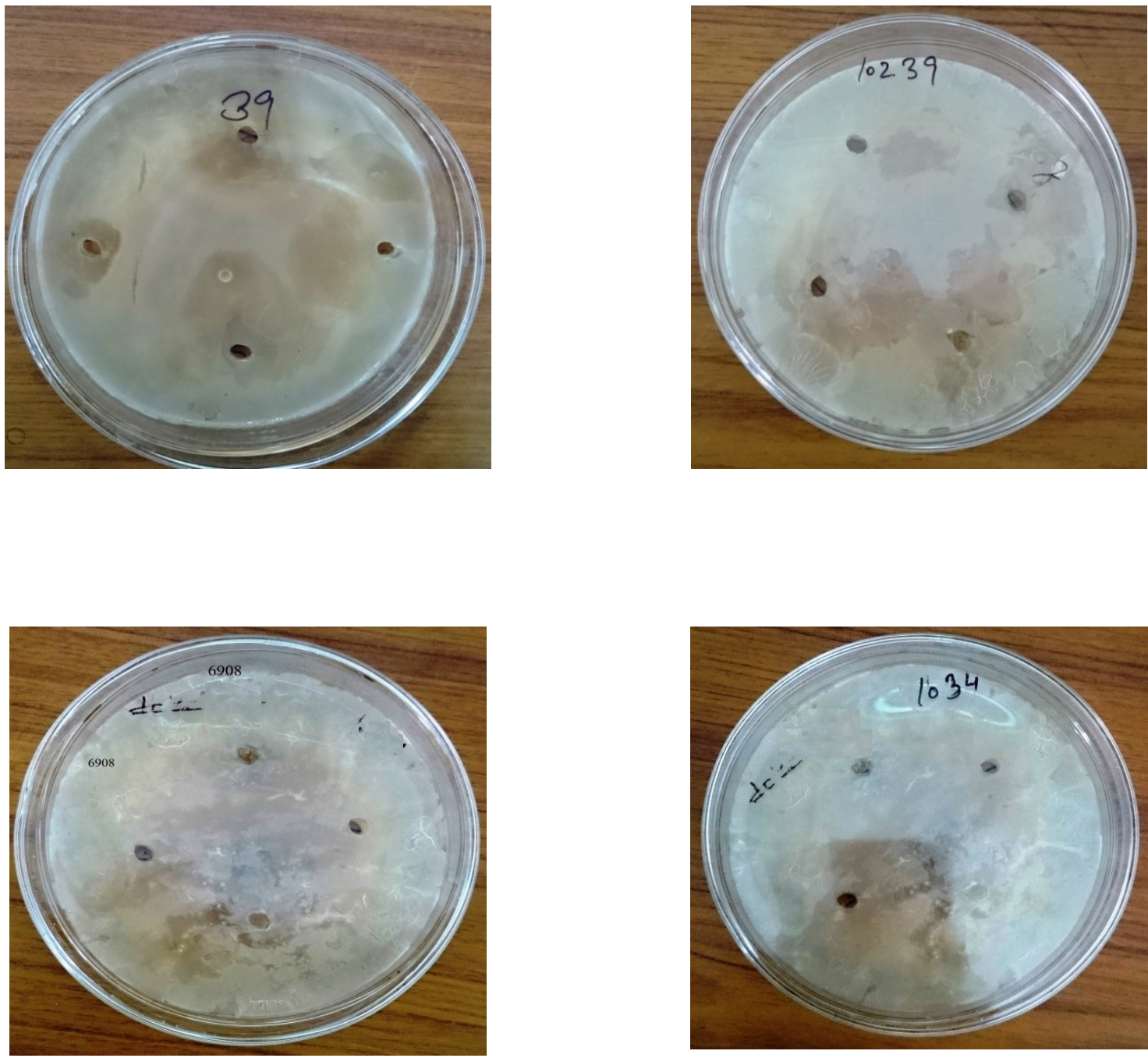


\section{Picture 1.4 showing zone of inhibition of test groups against four strains of bacteria}
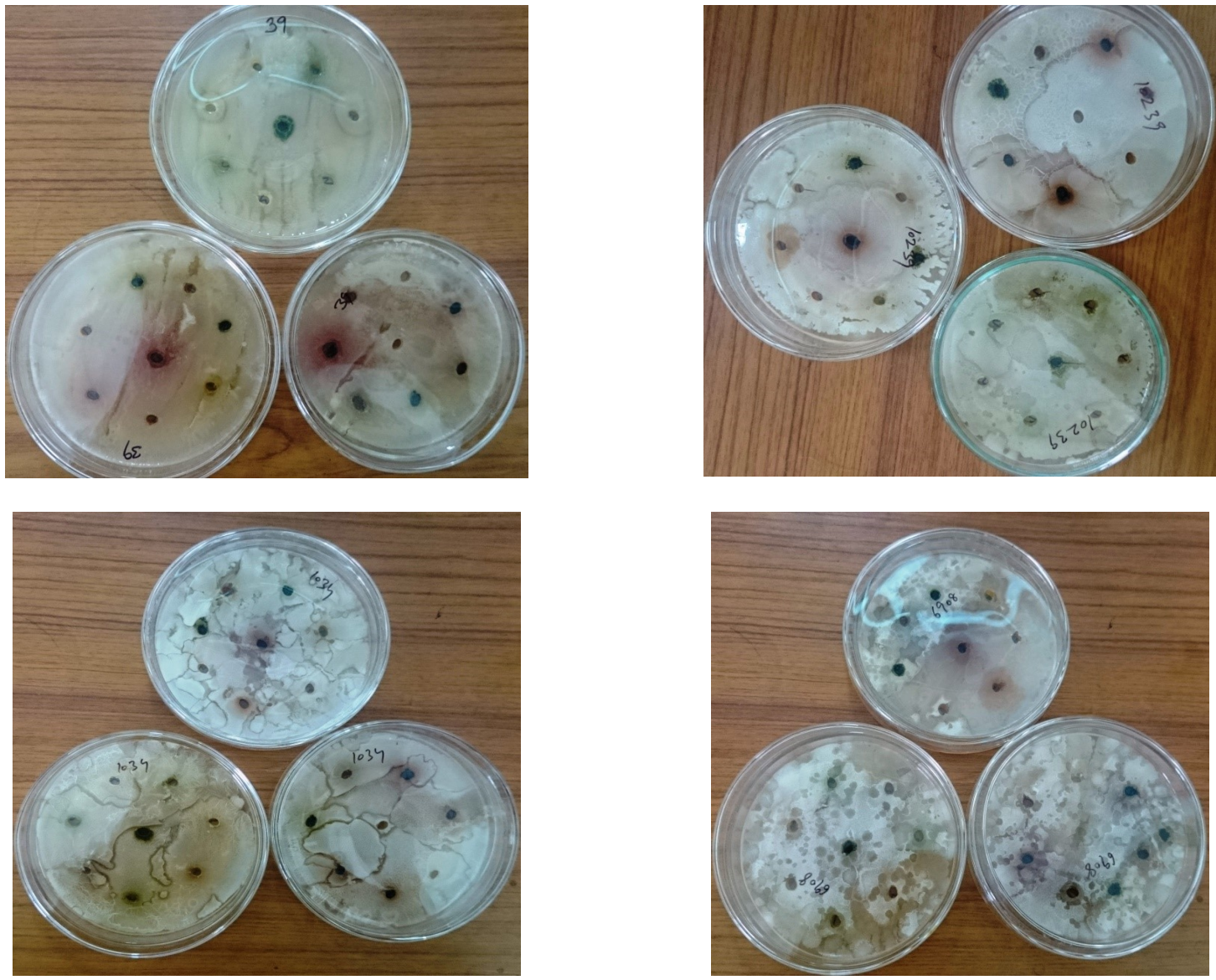

Activity index

Table 1.2 showing activity index of test drugs

\begin{tabular}{|l|r|r|r|r|r|r|r|r|r|r|r|r|r|}
\hline Bacteria & \multicolumn{3}{|l|}{ AESL } & \multicolumn{2}{l|}{ EESL } & \multicolumn{2}{l|}{ AEIL } & \multicolumn{2}{l|}{ EEIL } \\
\hline & $10 \%$ & $20 \%$ & $30 \%$ & $10 \%$ & $20 \%$ & $30 \%$ & $10 \%$ & $20 \%$ & $30 \%$ & $10 \%$ & $20 \%$ & $30 \%$ \\
\hline $\begin{array}{l}\text { Pseudomonas } \\
\text { aeruginosa }\end{array}$ & 0.35 & 0.45 & 0.55 & 0.35 & 0.4 & 0.4 & 0.3 & 0.4 & 0.45 & 0 & 0.4 & 0.6 \\
\hline $\begin{array}{l}\text { Staphylococcus } \\
\text { aureus }\end{array}$ & 0.28 & 0.32 & 0.44 & 0.24 & 0.28 & 0.28 & 0.36 & 0.36 & 0.6 & 0.4 & 0.44 & 0.44 \\
\hline Escherichia coli & 0 & 0.25 & 0.5 & 0.38 & 0.38 & 0.5 & 0.38 & 0.5 & 0.61 & 0.33 & 0.44 & 0.44 \\
\hline Klebsiella aerogenes & 0.22 & 0.25 & 0.33 & 0.22 & 0.29 & 0.37 & 0.59 & 0.66 & 0.70 & 0.33 & 0.37 & 0.55 \\
\hline
\end{tabular}

Graph 1.2 showing activity index of test drugs

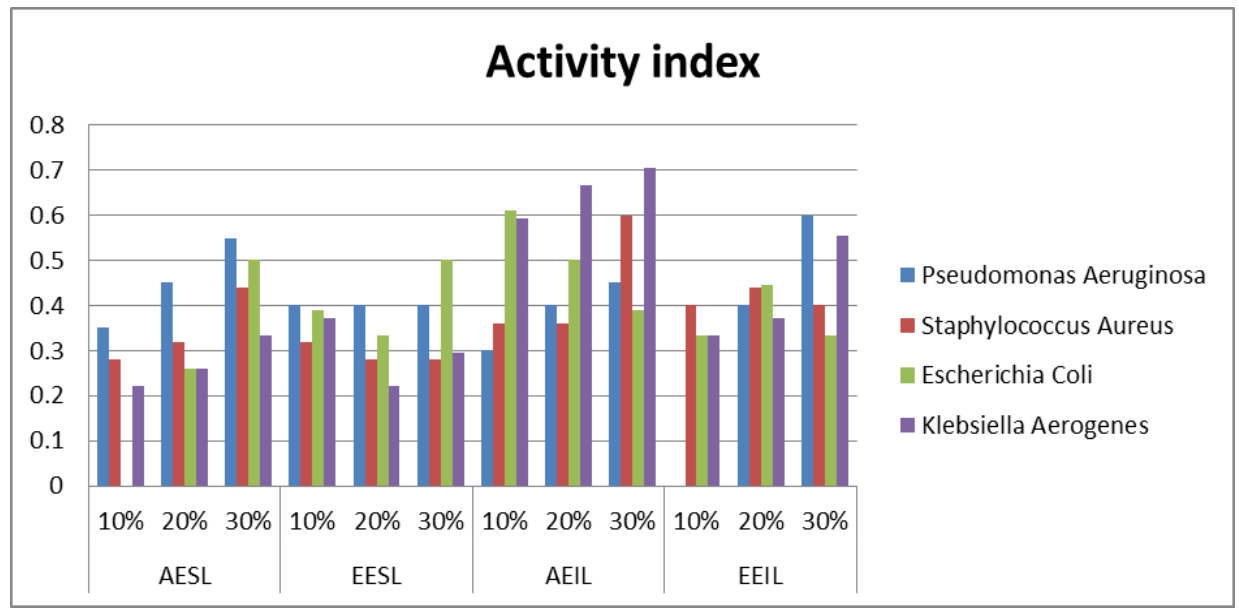




\section{IC $_{50}$ value:}

Table 1.3 showing $\mathrm{IC}_{50}$ value of test drugs

\begin{tabular}{|c|c|c|c|c|}
\hline Bacteria & AESL & EESL & AEIL & EEIL \\
\hline Pseudomonas aeruginosa & 1.778 & 4.64 & 2.268 & 1.801 \\
\hline Staphylococcus aureus & 2.463 & 23.26 & 1.778 & 3.686 \\
\hline Escherichia coli & 1.989 & 2.154 & 1.585 & 2.326 \\
\hline Klebsiella Aerogenes & 4.085 & 2.985 & 1.196 & 1.872 \\
\hline
\end{tabular}

Graph 1.3 showing $\mathrm{IC}_{50}$ value of test drugs

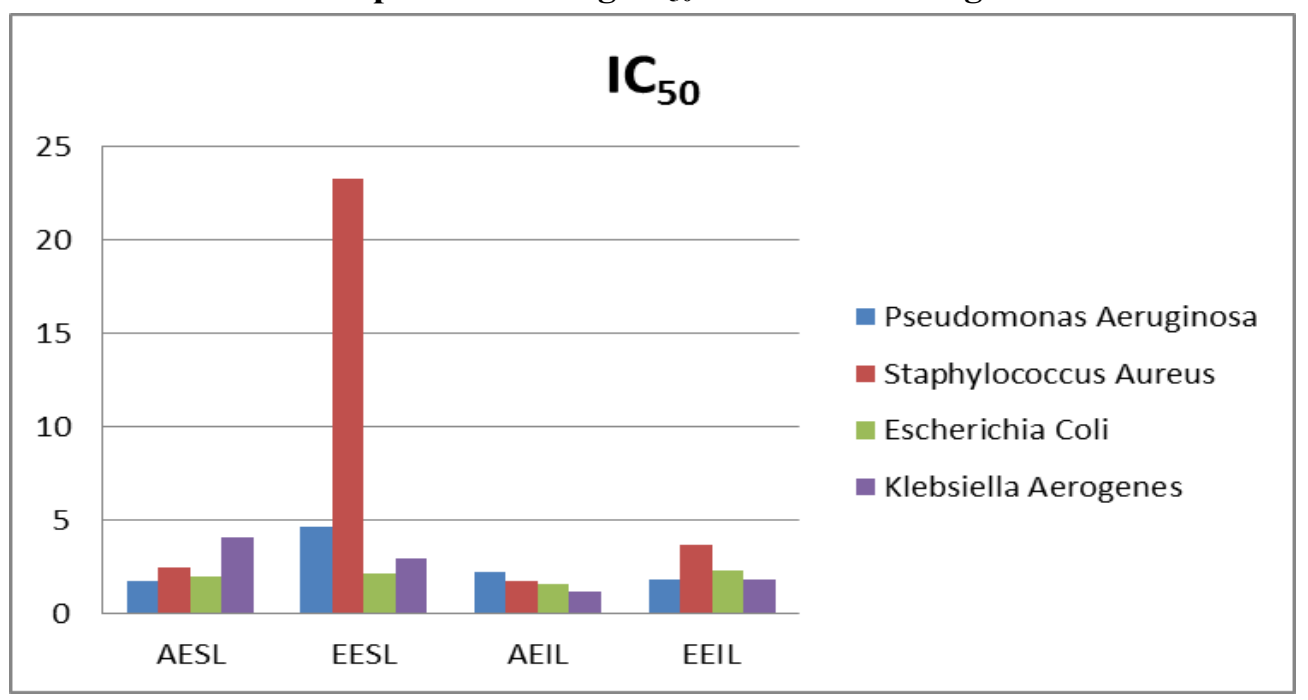

\section{Discussion:}

The bioassay results for antimicrobial activity of the Aqueous and Ethanol extracts of Balanites aegyptiaca (Linn.) Delile and Moringa oleifera Lam. are presented in Table 1. From the results it is very clear that both ethanol and Aqueous extracts of Balanites aegyptiaca (Linn.) Delile. and Moringa oleifera Lam. inhibited the growth of all the tested strains of bacteria. But aqueous extract of Ingudi showed significant results at 30\% concentration against Staphylococcus aureus in comparison to aqueous extract of Shigru \& ethanolic extracts of Shigru \& Ingudi. At all the three concentrations, it showed potent results against Klebsiella aerogenes. Ingudi's ethanol extract also showed potent action against Klebsiella aerogenes in comparison to aqueous extract of Shigru \& Ingudi, ethanolic extracts of Shigru.

The activity index of the test substance above 0.5 is considered as significant activity (8). Aqueous extract of Balanites aegyptiaca (Linn.) Delile has activity index of $0.6,0.61,0.70$ against $S$. aureus, $E$. coli, $K$. aerogenes respectively which proves its better efficacy than other samples.. Ethanolic extract of Balanites aegyptiaca (Linn.) Delile also shows good activity index of $0.6 \& 0.55$ against P.aeruginosa \& K.aerogenes respectively. Aqueous extract of Moringa oleifera Lam. shows good activity index only against P.aeruginosa of 0.55 .

Concentration required to inhibit $50 \%$ of Pseudomonas aeruginosa is lowest in Aqueous extract of Moringa oleifera Lam. $\left(\mathrm{IC}_{50}=1.778\right)$ which depicts its more potent action as compare to other Extracts of Balanites aegyptiaca (Linn.) Delile \& Moringa oleifera Lam .

Against Staphylococcus Aureus, Escherichia Coli, Klebsiella Aerogenes, $\mathrm{IC}_{50}$ is lowest in Aqueous extract of Balanites aegyptiaca (Linn.) Delile i.e. 1.778, 1.586, 1.196 respectively required killing $50 \%$ microorganism.

\section{Conculsion:}

The difference in the activity may be due to the different secondary metabolites present in the ethanol and water extracts. Different solvents have various degrees of solubility for different phytoconstituents (9). This indicates that the secondary metabolites act as an antimicrobial compounds, which either inhibit or kill the bacteria by different mechanisms.

Out of four tested microorganisms, three organisms i.e. Staphylococcus A ureus, Escherichia Coli, Klebsiella Aerogenes are affected by aqueous extract of Balanites aegyptiaca (Linn.) Delile upto a significant level which infers that it has more potent action in comparison to other extracts of Balanites aegyptiaca (Linn.) Delile \& Moringa oleifera Lam. Moringa oleifera Lam. is effective only in Pseudomonas aeruginosa.

Efficacy of leaves of Balanites aegyptiaca (Linn.) Delile is very much significant against Klebsiella aerogenes as compared to other microbes.

This study concludes that leaves of Balanites aegyptiaca (Linn.) Delile possess good antimicrobial effects as compared to Moringa oleifera Lam. 


\section{References:}

1. Billore K.V., Yelne M.B. et.al. Database on Medicinal Plants. Published by CCRAS. New Delhi. Feb. 2004; Vol. - 6; P-61

2. Sharma P.C., Yelne M.B.et.al. Database on Medicinal Plants. Published by CCRAS. New Delhi. 2000; Vol - 1; P-431

3. Laboratory guide for analysis of Ayurveda \& siddha formulations. Published by CCRAS. New Delhi. 2004; p-29,30

4. Perez C., Paul M. and Bazerque P. Antibiotic assay by agar-well diffusion method. Acta Biol Med Exp. $1990 ; 15 ; 113-115$.
5. Srinivasan D., Sangeetha Nathan, Suresh T., Lakshmanaperumalsamy P. Antimicrobial activity of certain Indian medicinal plants used in folkloric medicine. J. Ethnopharmacol. 2001; 74;217-220.

6. Jayanthi P., Antimicrobial activity of solvent extracts of Eichhornia crassipes (Mart.) Solms. Der Pharma Chemica. 2013; 5(3):135-140

7. https://en.wikipedia.org/wiki/IC50, cited on date 10/06/2016 and time 2:37pm.

8. Hosamath P.V. International Journal of Pharmaceutical Applications. 2011; 2(1):105-114.

9. Majorie MC. Plant products as antimicrobial agents.Clin.Microbial. Rev. 1999; 12(4): 564-582. 